\title{
EXTENSIÓN SEMÁNTICA DEL SUSTANTIVO POSPARTICIPIAL
}

Este estudio se basa en el análisis semántico sistemático de los sustantivos posparticipiales (y de formas afines) encontrados en un número de diccionarios españoles monolingües y en un diccionario breve español-inglés. Después de llegar a unas categorías semánticas tentativas por medio del análisis completo de las formas apropiadas del Diccionario Vox de 1964, y del Diccionario de la Universidad de Chicago de 1972, se tomaron datos adicionales de varias ediciones del Diccionario de la Real Academia Española (1970, 1984, 1986). Excluimos varias clases de sustantivos: 1) préstamos que ya en su lengua original se habían formado como posparticipiales (mascarada); 2) animados nominalizados (el conocido); 3) formas anticuadas o fosilizadas (abstracto, -udo); 4) compuestos directos que parten de una base participial (sobrecubierta).

Emanuel Georges trazó la historia de estas formas y su uso en numerosas obras medievales ${ }^{1}$, pero sin clasificar los significados de los derivados, principalmente por la extensión y variación de los significados de las raíces, y por el hecho de obrar en esto más de un sufijo² ${ }^{2}$ No cabe duda que el tema se complica por la

1 "Post-participial nouns: Their development from Latin to Romance", RPh, 21 (1968), 368-391; Studies in Romance nouns extracted from past participles, eds. J. R. Craddock and Y. Malkiel, University of California Press, Berkeley, 1970 .

2 Studies, p. 33. A base de su estudio de textos medievales producidos desde mediados del siglo x hasta ca. 1400, GEORGES establece nueve clases de derivados débiles (pp. 113-173). Aquí notamos un ejemplo y el número de ejemplos incluidos en su "Glosario": 1) -ado deverbal (cerrado; 38 ejemplos); 2) -ado denominal (tejado; 14 ejemplos); 3) -ido deverbal (oido; 7 ejemplos); 4) -ido 'sonido' (tronido; 10 ejemplos); 5) -ida deverbal (ida; 31 ejemplos); 6) -ada deverbal (andada; 66 ejemplos); 7) -ada denominal: 'golpe' (badajada; 28 ejemplos); 8) -ada denominal: 'concreto/colectivo' (braçada: 62 ejemplos); 9) varia (préstamos, transmisión múltiple, etc.; jornada; 23 ejemplos). Con este esque- 
potencialidad combinatoria múltiple de los sufijos -ado, -ada, -ido, $-i d a$ y las formas fuertes correspondientes (vuelto, vuelta) ${ }^{3}$. Aquí encontramos la intersección de la inflexión y la derivación. Además, es notable la variación dialectal y geográfica de estas formaciones, en especial la tendencia "americana" de extender unos usos de -ada. Aparte de las complejidades históricas, geográficas y semánticas, los sustantivos basados en el participio (especialmente los de base nominal) han competido con formas que muestran otros morfemas derivativos (-[c]ión, -m[ilento, -azo, -ía, -aje, $-e d a,-|\emptyset|-o /-e /-a$ posverbales, etc.). Con todo nos parece que las relaciones entre los significados de las raíces y los de las formas derivadas permiten un análisis que podría señalar unas tendencias generales, sin proponer una exactitud matemática. El siguiente análisis sugiere siete relaciones deverbales y diez relaciones denominales. Hasta el momento se han analizado casi 1500 significados (el número de palabras es menor, como resultado de la polisemia).

El repertorio de significados de estos sufijos ha sido trazado por varios estudiosos, desde la perspectiva diacrónica y desde la descriptiva. El sustantivo participial fue, en su origen, posverbal: -TUS 'acción'/-TUM 'resultado' se asociaba tanto con el participio como con la moribunda cuarta declinación, produciendo el sufijo - do y las formas fuertes correspondientes para expresar, según Federico Hanssen, "abstractos de carácter verbal" (peinado, barrido, pedido). Los terminados en -ado expresaban empleo u oficio (obispado). El plural neutro en -TA, interpretado popularmente como singular femenino (compárese hoja $<$ FOLIA) produjo - $d a$ formalmente y los conceptos de 'masa, colectivo,

ma, y puesto que Georges no se propuso un análisis semántico detallado, se combinan varios significados en la misma categoría. Tejado no es sinónimo de teja, pero filado puede serlo de hilo (< filo, pp. 144-145); bajo la categoría -ada (denominal, colectivo) se incluyen quesada (>quesadilla 'pastel de queso') y vallejada 'valle' (<vallejo). Según nuestro análisis, quesada pertenece a la clase 'colectivo preparado' (N4) y vallejada es del grupo N1, 'generalización/expansión' (semejante a erado 'era' <AREA, que GEORges considera parte de su categoría "varia", p. 171).

${ }^{3}$ Las formas como abstracto y trecho, que carecen de transparencia formal en el uso moderno, no se considerarán en el presente estudio. El análisis de Georges documenta y evalúa claramente una gran cantidad de formas fuertes fosilizadas; el enfoque nuestro se concentra más en el sentido perifrástico de raíz (accesible) más sufijo. Vuelta se incluye, pero no risa, ayuda. Véase J. M. BALDONADO, "Affixation and gender disinence in the Old Spanish postverbal nouns", RPh, 35 (1981), p. 72, n. 18. 
abstracto' semánticamente 4 . Surgieron luego dos funciones de-

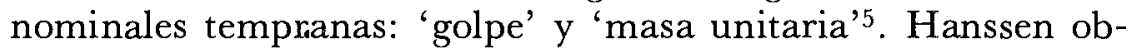
serva que, además de expresar 'una acción y su efecto' (ojeada, partida, risada, herida) y 'golpe' (cuchillada, patada), el sufijo -ada forma denominales que indican 'la cosa de que es principal ingrediente lo significado por la raíz' (nevada, limonada), 'contenido' (carretada, cucharada), 'conjunto o tropa' (mesnada< <esón, peonada) y 'acción propia de cierta clase de personas' (hombrada) ${ }^{6}$.

Investigando el uso de estos sufijos en el habla popular de Chile, Rodolfo Oroz da numerosos ejemplos de la función semántica 'acción y efecto', muchas veces en competencia con otros sufijos, y ocasionalmente con concretizaciones semánticas (desvelada 'desvelo', enlazada 'enlazadura', revisada 'revisión', dormida 'acción de dormir, lugar donde se pernocta'). Empleadas con raíces nominales, las formas en -ada (a veces -ado, -ida, -ido) expresan, según Oroz:

a) 'golpe de' o 'golpe en' (es decir, de primitivo instrumental o de primitivo pasivo): talonada 'golpe que se da con el talón'

b) 'medida' o 'cantidad': huinchada '10-25 metros, según el largo de la huincha o cinta para medir'

c) 'la calificación de una acción' (aquí Oroz combina 'acción propia de' [gallada 'audacia'] con 'expansión/aumentativo' [correntada 'corriente impetuosa de agua'] y con 'acción y efecto' [sentada 'acción de sentarse'])

d) 'conjunto de personas o cosas de la misma categoría': alumnado, bueyada

e) 'lo que cabe en un objeto': cachada 'el contenido de licor en el cacho o vaso'; pañuelada 'lo que cabe en el pañuelo'

f) 'un guiso o alimento': arrollado 'carne de cerdo que cocida y aderezada con ingredientes, se acomoda en rollo formado de la piel, también cocida, del mismo animal'; naranjada

g) 'un objeto': alfombrado 'alfombra que cubre una pieza'7.

${ }^{4}$ Georges, Studies, p. 87; Federico Hanssen, Gramática histórica de la lengua castellana, Max Niemeyer, Halle, 1913, p. 133. Véase A. KATZ Levy, "Review of Annegret Alsdorf-Bollée, Die lateinischen... y Georges, Studies...", RPh, 26 (1972), p. 413.

${ }^{5}$ Georges, Studies, p. 17.

${ }^{6}$ Hanssen, Gramática, pp. 133-134.

${ }^{7}$ Rodolfo Oroz, La lengua castellana en Chile, Universidad de Chile, Santiago, 1966, pp. 225-229. 
Gary A. Scavnicky resume los usos "normales" peninsulares así:

-ada: a) acción y efecto (llegada, pinchada)

b) golpe o herida: primitivo instrumental (martillada, patada)

c) golpe: primitivo pasivo (pernada< $<$ ierna)

d) lo que cabe en el primitivo (cucharada)

e) agrupación o conjunto de cosas homogéneas (cabrada, estacada)

f) acción propia de cierta clase de personas (alcaldada, muchachada)

g) acción propia de animales aplicada a personas (chanchada, burrada)

h) duración de tiempo (añada, mesada)

-ado: a) congregación o cuerpo de varias personas investidas de cierta dignidad (estudiantado, profesorado)

b) el título o grado académico (doctorado, lectorado)

c) en formas adjetivales, la forma de, o semejanza con lo que se designa con el primitivo (conchado, lunado)

d) en formas adjetivales, la posesión de la cosa expresada por el primitivo (barbado, lobulado) ${ }^{8}$.

Las formas en -ida, -ido, menos frecuentes, se resumen en el uso centroamericano (o americano) en la expansión del sufijo -ida, sinónimo de - ada (leida 'acto de leer') y la del sufijo -ido 'sonido'9.

A pesar de la utilidad de estas enumeraciones, en lo tocante al uso actual quedan algunas preguntas. ¿Cómo se describe la relación entre el 'objeto' primitivo (alfombra) y el derivado (alfombrado)? Cuando el sufijo - ada se usa con bases verbales ¿distingue entre 'acción' y 'efecto'? ¿Cómo se concretiza el efecto? El sufijo -ado ¿no produce sustantivos de semejanza formal (lenguado 'especie de pez') además de producir adjetivos? ¿Pertenecen a la misma clase las "acciones propias"' de personas y las de animales? Los primitivos de esta(s) clase(s) ¿se refieren siempre a seres animados? ¿Puede ser - ada de añada, mesada una metáfora que incluye la noción de 'capacidad o expansión', por lo menos si el primitivo (año, mes) ya indica 'duración'? Al formar los nombres de los guisos y alimentos, ¿cuál es la relación entre el primitivo y el derivado? Si estos sustantivos se refieren a "ingredientes principales" ¿repre-

${ }^{8}$ GARy A. SCAVnICKy, Innovaciones sufijales en el español centroamericano, Juan de la Cuesta, Newark, DE, 1987, pp. 7-8.

9 Ibid., p. 41. 
sentan una especie de colectividad? ¿Cuál es la frecuencia relativa de - $d o$ y de - $d a$ con los significados expuestos? ¿Qué movimiento han causado las posibles ambigüedades? ¿En qué casos se disocian el significado del sufijo y el de la base? El análisis de un número de ejemplos sugiere las conclusiones que ofrecemos a continuación.

En la clasificación de significados representa un problema especial el caso de una palabra como losado, por ejemplo, cuya función semántica varía según su interpretación como colectivo denominal $(<$ losa $)$ o como producto deverbal $(<\text { losar })^{10}$. Esta posibilidad lleva a la coincidencia de funciones; la existencia del losado se debe a una intervención humana (losar) realizada mediante el uso de una cantidad indeterminada de entidades (losas) o de masa (melado $<$ miel). Las palabras como losado no figuran en las cifras que siguen. Por supuesto, es distinto el caso de mela$d o$, denominal; se forma de miel ya que no existe el verbo *melar. (Aquí nos limitamos a los vocablos considerados existentes por su inclusión en las fuentes utilizadas.) En cambio, barrido, deverbal, se deriva de barrer y no de barra/barro. Las cifras que siguen incluyen los significados clasificables de esta manera.

\section{Signficados deverbales}

V1. Resultado abstracto/evento. El sustantivo derivado es el nombre de un acontecimiento, un ejemplo de la actividad indicada por la raíz verbal:

caida, conversada, despedida, venida...

formas en $-d o: 100$.

formas en $-d a: 194$

formas fuertes en $-0: 3$

formas fuertes en $-a: 9$

$\mathrm{El}$ acontecimiento puede ser interpretado como una acción, perfectiva y contable, o como un resultado abstracto, imperfectivo y muchas veces no-contable. (Compárese caída en inglés, 'fall, falling'.) Como resultado abstracto, su significado se acerca al del infinitivo (la venida mía $=$ el venir yo 'my coming').

V2. Producto (resultado concreto/entidad). El sustantivo derivado es el nombre de una entidad concreta y contable cuya existencia resul-

${ }^{10}$ Georges, Studies, p. 55. 
ta de la realización de la actividad indicada por la raíz verbal: quemada, resultado, revisada, supuesto...

formas en -do: 135

formas en $-d a$ : 80

formas fuertes en $-0: 10$

formas fuertes en $-a$ : 4

V3. Sonido. El sustantivo derivado es el nombre de un producto audible que resulta de la realización de la actividad indicada por la raíz verbal ${ }^{11}$ :

berrido, chillido, ladrido, pitido...

formas en -ido: 42

V4. Lugar asociado. El derivado es el nombre del lugar donde ocurre la actividad indicada por la raíz verbal:

arado, colada, desplayado, dormida...

formas en -do: 14

formas en $-d a: 23$

formas fuertes en $-0: 2$

formas fuertes en $-a: 1$

V5. Objeto/entidadiactivo. El derivado es el nombre de un objeto o el del material que ejerce la actividad indicada por la raíz verbal: cubierta, oido, seguido, surtido...

formas en -do: 37

${ }^{11}$ Véase J. R. Craddock and E. S. Georges, "The Hispanic sound suffix -ido"', RPh, 18 (1963-1964), 87-107. Según estos autores, el desarrollo de un sufijo -ido sistemáticamente aplicable a la derivación deverbal de sonidos es una característica peculiar del romance hispano, pero LeVy (art. cit., pp. 417-418) señala un paralelo en sardo, en que existe la combinación de la raíz de la primera conjugación y la vocal $-i$ - . La productividad de -ido parece haber partido de una generalización de RUGITUM o a la de SÓNITTUM$>$ SONÍTUM; además hay evidencia de confusiones entre -ARE e -IRE entre estos verbos y la influencia posible de disimilaciones vocálicas. SCAVNiCKY, op. cit., p. 142, siguiendo en parte a Boyd-Bowman, señala unas formaciones "americanas" de -ido: cantido, llorido, toquido 'sonido que produce un objeto que se toca como campanas, puertas'. Según Oroz, op. cit., p. 229, los sustantivos en -ido usados en Chile son los de la península, salvo unas formaciones "vulgares" (volido "vuelo'): el caso es excepcional por no indicar sonido como los otros ejemplos citados por Oroz (silbido, aullido). Sobre el uso de -ido para formar adjetivos posnominales, véase STEVEN N. DWORKIN, Etymology and derivational morphology: The genesis of the Old Spanish denominal adjectives in '-ido', Tübingen Verlag, Tübingen, 1985. 
formas en - da: 11

formas fuertes en $-0: 3$

formas fuertes en $-a: 3$

V6. Objeto/entidad pasivo. El derivado es el nombre del objeto que, aun existiendo antes de ella, recibe la actividad indicada por la raíz verbal:

contenido, pertenecido, planchado, lavado...

formas en $-d o: 26$

formas en $-d a: 20$

formas fuertes en $-0: 3$

formas fuertes en $-a: 3$

V7. Tiempo. El sustantivo derivado es el nombre del periodo de tiempo durante el cual ocurre la actividad indicada por la raíz verbal:

asentada, madrugada, salida, sentada...

formas en $-d a: 7$

\section{Significados DENOMinALES}

N1. Sufijo "vacio"/generalización. El derivado no exhibe ninguna diferenciación (o exhibe muy poca) del primitivo. A veces, especialmente en los primitivos que indican lugar, se añade una sutil ampliación espacial ${ }^{12}$ :

bolada, ijada, lechada, llanada...

formas en $-d o: 8$

formas en $-d a: 55$

Hay cambios de género (barrio $>$ barriada, tierra $>$ terrado).

N2. Intensificador. El derivado tiene un significado claramente más fuerte que el del primitivo:

correntada, churretada, plomada, riada...

formas en -ada: 25

${ }^{12}$ Compárese erado 'era' (sufijo "vacio") de los ejemplos de Georges (Studies, p. 171). La glosa de vallejada 'valle' (p. 169) puede ser la neutralización del diminutivo y el aumentativo (vallejo 'valle pequeño'), o más exactamente la palabra se refiere a la extensión o expansión del vallejo, como la medida de su existencia física. La noción de 'generalización espacial' puede interpretarse como un matiz débil del grupo N2, 'intensificador'. 
N3. Colectivo absoluto. El derivado se refiere a un grupo o a una cantidad del primitivo:

indiada, juncada, vacada, yeguada...

formas en $-d o: 33$

formas en -ada: 78

Los cambios de género son frecuentes (alfombra >alfombrado 'conjunto de alfombras'; potro $>$ potrada).

N4. Colectivo preparado. Un grupo o una porción del primitivo causa la producción del derivado, frecuentemente una confección con otros elementos o ingredientes, hecha con la intervención humana:

bizcochada, cebollada, limonada, melado...

formas en - do: 53

formas en $-d a: 49$

N5. Acción/comentario tipicos de. El derivado se refiere a una sola unidad de acción asociada con el primitivo (generalmente, el primitivo es animado y el derivado es despectivo):

bobada, cadetada, domingada, niñada...

formas en -ada: 93

N6. Capacidad/medida. El derivado se refiere a una sola unidad de medida contenida en el primitivo (en inglés, '-ful, -worth, volume, length, portion'):

bocado, brazada, cestada, nidada...

formas en $-d o: 4$

formas en -ada: 84

N7. Golpe (y sus extensiones). El sustantivo derivado se refiere a un golpe o a un pego hecho con una parte del cuerpo, un arma u otro instrumento, con extensiones como 'herida que resulta del golpe', 'mancha producida por él'; también un golpe que se recibe en una parte del cuerpo:

cabezada, cornada, lanzada, pedrada...

formas en -ada: 75

N8. Movimiento. El sustantivo derivado se refiere a un movimiento de alguna parte del cuerpo, o de otro instrumento. El movimiento en general no incluye la noción de contacto que es evidente en el grupo N7:

bonetada, gorrada, plumada, uñada... 
formas en -ada: 19

N9. Metáfora de forma. El sustantivo derivado se refiere a un objeto, típicamente una planta o un animal, semejante al primitivo en su forma o en otro rasgo físico:

esponjado, estrellada, flautado, lenguado...

formas en $-d o: 6$

formas en $-d a: 5$

N10. Oficio/territorio/tiempo de. El derivado se refiere al cargo oficial de un número reducido de primitivos, o al tiempo o territorio de una cantidad algo más numerosa de primitivos, principalmente animados:

apostolado, arzobispado, consulado, rectorado...

formas en -ado: 34

Naturalmente estas clases se proponen más como fuerza organizadora que como resolución absoluta, pero ofrecen un panorama de los significados documentados. Sin embargo, no revelan unos rasgos que merecen clarificación: casos de coincidencia (producto como colectivo preparado, $\mathrm{V} 2 \sim \mathrm{N} 4$ ); variación morfológica; competencia entre sufijos; ambigüedades sistemáticas (repetidas) según varias clases de primitivos; disociación de morfemas.

La coincidencia producto-colectivo, como hemos visto, se da por casos de posibilidad doble en V2 o en N4. En general, si falta el primitivo nominal, el significado se ha considerado como V2. La clasificación mixta es frecuente en otras clases también: pincelada 'pincel' se incluye bajo N1 (sufijo "vacío", clasificación automática si la glosa repite la palabra definida), pero otra acepción, 'acción y efecto de pincelar', se ha interpretado como V1. Estos datos sugieren que la pertenencia a los grupos establecidos cuenta con unas ambigüedades sistemáticas:

1. (salida) 'lugar de evento', 'tiempo de evento'

2. (entrada) 'lugar/tiempo de evento', 'instrumento'

3. (vista) 'objeto pasivo', 'instrumento/facultad'

4. (gallegada) 'acto típico de', 'colectivo'

5. (invernada) 'lugar de', 'sufijo vacío'

6. (plumada) 'cantidad contenida', 'producto', 'movimiento'

7. (tajada) 'producto', 'objeto activo'

Unos mecanismos, sin embargo, han tenido un efecto de distinguir funciones, evitando así la polisemia, entre ellos el uso de 
los despectivos -ote o -ete (manotada 'golpe dado con la mano', manada 'porción de una cosa que puede cogerse de una vez con la mano') y el contraste -o/-a (puñado 'lo contenido en el puño', puñada 'puñetazo').

Casos frecuentes de variación morfológica son: 1) el infijo -ar- (llamarada, lenguarada, fogarada, fumarada, uñarada, quijarada, etc. $)^{13}$ y sus variantes -arr $(0)$ - y -er- (zaparrada<zarpada; testara$d a \sim$ testerada<testa); 2) los prefijos parasintéticos $a-$ y (más comúnmente) en- em-, sobre todo en las clases de 'producto' y de 'metáfora formal': enjabonado, empapelado, empedrado, entruchado (V1); encintado y encaballado (V2); entripado 'enojo', raro por ser abstracto (<tripas, N4); 3) el sufijo despectivo -ote, -ota (manotada, risotada, pajarotada, picotada, capirotada < CAPPA, que se combina únicamente con bases nominales; con menos frecuencia, -ucho, -ocho (patochada 'disparate' < pata).

La polisemia sistemática (particularmente en las formas en -ada) se basa en categorías semánticas de los primitivos. El sufijo -ada 'golpe con' nos proporciona formas contrastivas con homófonos en -ada 'cantidad contenida en' cuando, como en el caso de palada, paletada, capilluda, un recipiente de contenido puede usarse como arma potencial, o como objeto de movimiento. El significado 'golpe recibido' es otra fuente de ambigüedad (cabezada 'golpe que se da con la cabeza o se recibe en ella', 'cada movimiento de cabeza del que se va durmiendo sin estar acostado'). Nota Georges que el significado 'golpe recibido' se encuentra mucho menos que el de 'golpe dado'; en sus datos (medievales) apenas se hallan seis ejemplos del significado 'golpe recibido' con el primitivo como objeto pasivo, como en rodillada, cabezada ${ }^{14}$. Un ejemplo, ijada, extiende la noción de 'golpe recibido' a la de 'dolor de ijada' $\left(<{ }^{*} i j a<\right.$ ILIA, neutro plural, 'entrañas, vientre' $)^{15}$. No obstante, estas formaciones en -ada están en distribución complementaria con las de -ada 'acto/comentario típico de' (N5), puesto que éstas tienen normalmente bases animadas, $\mathrm{y}$ aquéllas siempre vienen de primitivos no-animados ${ }^{16}$.

Entre las relaciones más problemáticas y más complejas se

13 Véase Georges, Studies, p. 69.

${ }^{14}$ Ibid., p. 65.

${ }^{15}$ Ibid., p. 69, n. 77.

${ }^{16}$ Scavnicky dice que -ada 'acción típica de' se emplea únicamente con animados (Innovaciones, p. 26). Pero encontramos domingada 'actividades (típicas) del domingo', carnavalada, sanmiguelada, en que la base es un evento u otro periodo de tiempo durante el cual ocurre la acción típica. 
encuentran los usos de -ada 'colectivo preparado' (N4). Este morfema, empleado literalmente en limonada, llega a utilizarse con primitivos que no indican ingredientes sino que representan una relación oblicua o "disociada": gloriada 'especie de ponche', carraspada 'bebida compuesta de vino tinto aguado... con miel y especias' (< carraspear 'tener ronquera'). Compárese en inglés, lemonade (literal, 'bebida de limones con agua, azúcar, etc.') con $\mathrm{Ga}$ torade (morfema disociado, marca registrada, 'bebida nombrada por los Gators, el equipo de fútbol americano que primero lo popularizó'). Otros 'colectivos preparados' comestibles y potables muestran orígenes más oblicuos, sujetos al influjo de la contaminación intra-idiomática o del préstamo extranjero. Es normal que el léxico de las comidas y bebidas se vea influido por estos factores; lo esencial en este contexto es que el morfema -ada se ha divorciado de su significado primitivo de 'confección de' más sustantivo. Aquí notamos casos como capirotada 'aderezo para otros manjares, plato criollo, fosa común' (< gascón capirot<CAPPA); papirotada, influido por papo; pa(m)pirolada 'salsa de pan y ajos', tal vez influido por papo y por $p a n^{17}$; ginebrada 'torta de hojaldre' (posiblemente < Ginebra, o <jengibre $>$ *jengibrada cruzado con Ginebra, o < francés antiguo gen obrada 'bien trabajada, bien amasada' $)^{18}$; ginestada 'salsa de leche, harina de arroz, especias' $(<\text { genista, por su semejanza de color })^{19}$; gratonada 'guisado de pollo con tocino, almendras, etc.' (< <rancés creton craton 'pedazo de tocino' o < francés gratin 'plato hecho con pan rayado' < gratter 'rascar, rayar'20. La extensión de -ada a otros préstamos produce chaconada 'tela empleada para hacer ropa de mujer' < francés jaconas < jaconat< Jagganath 'pueblo indio donde se fabricaba la tela' ${ }^{21}$; chambado 'cuerna, vaso rústico' (<portugués chamba 'pierna, cuerno' > 'forma de vaso o copa'; compárese el francés jambe 'pie de copa'; es del grupo N9); chanada 'engaño, acto hábil e inteligen-

${ }^{17}$ Joan Corominas y José A. Pascual, Diccionario crítico etimológico castellano e hispánico, Gredos, Madrid, 1980, t. 1, pp. 827-828.

${ }^{18}$ Ibid., t. 3, p. 150.

${ }^{19}$ Loc. cit.

${ }^{20} \mathrm{Ibid}_{\mathrm{n}}$, t. 3, p. 202

${ }^{21}$ La relación precisa con -ada es problemática en este caso, ya que la forma francesa temprana llevaba - $t$. Véase PAUL RoBert, Dictionnaire aljabétique et analogique de la langue française, Société du Nouveau Littré, Paris, 1963, t. 4, p. 100. La tardía documentación de jaconat (segunda mitad, siglo Xvin)

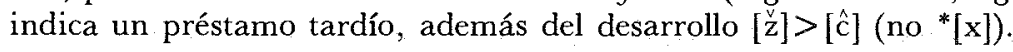


te' (< caló y gitano chanar 'saber, entender') ${ }^{22}$. Existe también la opción de -ada -ado para hacer distinciones dentro de la clase de 'colectivo preparado', otra vez con posibles variaciones regionales: mantecada 'rebanada de pan untada con mantequilla; especie de bollo de harina' y mantecado 'bollo amasado con manteca de cerdo; sorbete de leche, azúcar y mantequilla'. La distinción entre 'colectivo absoluto' y 'colectivo preparado' explica la polisemia en casos como sesada 'fritada de sesos' y sesada 'sesos'.

La versión - ada 'unidad de medida' a veces se disocia: cuchara$d a$, literal, pero obrada 'labor campestre diaria; medida agraria'; yugada 'huebra, espacio de tierra de labor que puede arar una yunta en un día'; tacada 'serie de carambolas seguidas sin soltar el taco'. En obrada y yugada la noción de medida diaria es implícita; una tacada puede ser o "un golpe dado con el taco a la bola de billar' (N7) o una serie de movimientos que incluye un elemento de medida de duración. Algunos colectivos ahora se usan como términos generales de abundancia: porrada, porretada 'un montón de cosas'; nubada 'abundancia de algo'.

Otras derivaciones de interés son acompañado 'atarjea o caja de ladrillos de las cañerías', que tal vez ejerce el acompañamiento de las cañerías, protegiéndolas (V5) ${ }^{23}$; tostada 'conversación aburrida, visita fastidiosa, molestia', significado atribuido al uso argentino, de tostar (compárese tostón 'lata'); caído 'línea oblicua del papel pautado para aprender a escribir' (V5, ya que la inclinación cae de un lado de la hoja al otro); embolado 'en el teatro, papel corto y desairado; artificio engañoso' (<oc. ant. bola, posiblemente relacionado con el latín EMBOLISMU 'intercalación'); enfosado 'encebadamiento, enfermedad que contraen las caballerías por beber demasiada agua después de haber comido' (probablemente < FOSSA 'excavación, canal', compárese husillo 'canal de desagüe'). Martín Alonso, en una etimología discutible, deriva el verbo enfosar(se) del latín FARCIRE 'engordar, cebar'24. Capetonada, forma confundida con capa ( $>$ capeta $>$ capetona) refleja la derivación de chapetonada 'vómito violento que ataca a los europeos que pasan la zona tórrida', <chapetón 'europeo recién llegado a América; inexperto, bisoño en las dificultades del país', probablemente <chapin 'chanclo con suela de corcho', 'en que se andaba incó-

22 Corominas-Pascual, Diccionario, t. 2, p. 321.

${ }^{23}$ Compárese Scavnicky, Innovaciones, p. 28; la palabra parece ser colombianismo.

${ }^{24}$ Enciclopedia del idioma, Aguilar, Madrid, 1958, t. 2, p. 1711. 
modamente y metiendo ruido, por alusión al andar pesado del que sufre de niguas en los pies, de las cuales solían padecer los inexpertos en la vida tropical'"25. Cachupinada 'convite casero, banquete, reunión de gente cursi' probablemente es reflejo de cachupin ( gachupin) 'español que se establece en la América Hispana' < portugués cachopo 'niño' o, según Corominas, 'tronco hueco o seco que se le aplicó al español por su ignorancia'26. Aquí el colectivo, posiblemente asociado con la noción de 'acto típico', se extendió para referirse al evento a que asisten las personas indicadas por la raíz. Son notables también las concretizaciones de las estaciones: estivada 'terreno inculto cuya broza se cava y quema para cultivarlo' (<estio) y otoñada 'pasto del otoño' (pero también N1).

El español antiguo cor, y la versión moderna corazón, ofrecen unos ejemplos de lo dinámico de estas relaciones. Corada, de cor, demuestra el desarrollo típico de N1, de ensanchamiento espacial 'conjunto de las entrañas; hígado y bofes'. Corazonada familiarmente tiene el mismo significado de 'asadura de un animal', además de 'unidad de acción' o 'golpe' figurativo: 'impulso espontáneo, presentimiento'; su variante apocopada coraznada se reifere al 'corazón de pino' (N1) o al 'guisado de corazones' (N4). Llovido 'el que se embarca clandestinamente', es una nominalización animada que no incluimos en las cifras; es un caso atípico por basarse en un verbo normalmente intransitivo. Suelta 'cordel con un pequeño peso que se ata a una pata de la gallina para dificuitarle la marcha' implica la contradicción de que la gallina puede caminar suelta, aunque el acto de atar parece indicar lo contrario ${ }^{27}$. Los sustantivos abstractos son pocos, pero hemos documentado entripado 'enojo', parada 'jactancia', el mexicanismo facetada 'gracia afectada; (tratándose de niños) gracia, monería', tal vez relacionado con faceto 'chistoso sin gracia, patoso'; sorrostrada 'insolencia' (<'dificultad, obstáculo', < so y rostro; compárese sobarbada). Podemos mencionar aquí también regalada (<REGALEM) 'caballeriza real donde están los caballos de regalo; los caballos que la componen'. Como caso único de sustitución tenemos perdido 'sustituto por impresos perdidos; cierto número de ejemplares tirados de más en cada pliego, para suplir

${ }^{25}$ Corominas-Pascual, Diccionario, t. 2, p. 330 . Estos autores critican la etimología académica, que supone como fuente chapa.

${ }^{26}$ Ibid., t. 1, pp. 725-726.

27 Ibid., t. 1, p. 23. 
los imperfectos o inútiles'. Aunque sería posible extender más esta lista, los casos referidos proporcionan un concepto de la variabilidad de los significados y de las relaciones entre primitivos y derivados. Estos casos son "residuos", y no se han incluido en las cifras indicadas arriba.

Otros sufijos compiten con los participiales, con acepciones similares. Para expresar los abstractos deverbales, unas alternativas generalmente más eruditas de nuestra clase V1 son: $-m(i)$ ento, -(c)ión, -(d)ura, -ancia y -encia (en latín, -MENTUM y -TIONEM ya gozaban de gran prestigio en el lenguaje técnico ${ }^{28}$. Los sufijos - $e d a,-e d o$, usados con bases apropiadas, formaron nombres de arboledas, en competencia con -ada (colectivo absoluto: N3). Dentro de este grupo hay distinciones posibles (robleda 'robledo de gran extensión'). Georges indica que el uso de -azo (<ATIO, pero asociado con -ACEU, por -ada, N7) aumentó con la necesidad de expresar de un modo más fuerte e inmediato el concepto de 'pego, tiro' en la época de la invención de las armas de fuego $^{29}$. Además, según Malkiel, la "incómoda polisemia de -ada" puede haber favorecido la adopción de formaciones en -azo, combinando las nociones de 'aumentativo' y 'golpe, herida'30. Com-

${ }^{28}$ Levy, art. cit., p. 413; Georges, Studies, p. 55. Un estudio muy valioso para la historia general de los abstractos derivados de adjetivos es el de $\mathrm{S}$. N. Dworkin, "Studies in lexical loss: The fate of Old Spanish postadjectival abstracts in -dad, -dumbre, -eza, and -ura", BHS, 66 (1989), 335-342. Aunque su análisis no se concentra en los abstractos verbales, Dworkin señala la productividad general de sufijos de la forma canónica -VCV (p. 337).

${ }^{29}$ Georges, Studies, p. 87; Y. Malkiel, "The two sources of the Hispanic suffix -azo, -aço", Lang, 35 (1959), pp. 251-255.

${ }^{30}$ MALKIEL, "Sources", p. 257. Makiel indica que, para Cuervo, -ada se refería al efecto de un golpe más que -azo, que en su uso literal, le da énfasis a la fuerza o al ímpetu del movimiento (p. 212, n. 53). Malkiel concluye que -ada se refiere a la acción perfectiva y a su resultado inmediato, con matices de rapidez, precipitación repentina y violencia, pero en general sin referencia al ruido producido (p. 256). Malkiel también señala una variedad de formas que incluyen el morfema -ote, -ete con -azo (p. 201) y la distinción posible entre, por ejemplo, escobazo 'golpe con la escoba' y escobada 'barrido, movimiento de la escoba' (p. 202, n. 19). Según Malkiel, una "preferencia de variación", ha causado el desuso de palabras como codada (hoy se prefiere codazo), por querer el hablante evitar las secuencias -dada, -tada (p. 202). El análisis de las cifras del Diccionario inverso del español de Hermenegildo de la CAMPa (Narcea, Madrid, 1987, que se basa en la edición de 1984 del Diccionario de la Real Academia Española) muestra que las terminaciones - dada y -tada son muy frecuentes. De las 3078 palabras terminadas en -ada, las terminadas en -dada representan 114 de los casos (el 3.7\%), y las de -tada son 330 (el 10.7\%). Es decir, -dada y -tada ofrecen 444 casos (el 14.4\%). Por otra arte, el número de 
párense, por ejemplo, candilada 'aceite derramada de un candil' (N6) con candilazo 'golpe dado con un candil'; sartenada 'lo que cabe en la sartén' (N6) con sartenazo 'golpe dado con ella'. Unos cuantos sustantivos en -ada se refieren a impuestos ( español antiguo -adgo $\mathrm{y}$, a través del francés, -aje: tonelada $\sim$ tonelaje 'derecho pagado por los buques' 31 . Mientras tanto, -ería compite con -ada 'colectivo absoluto': truhanada 'truhanería', vacada 'vaquería'. -Ado (N10) varía con el cultismo -ato (califato); del italiano proviene -ata (caminata, cabalgata).

Es notable la propagación de - $a d a$ (y, aunque sea menor, la de - [a]do) en los dialectos americanos. Gary Scavnicky, en su estudio de los sufijos empleados en América, especialmente en la América Central, señala tres clases de "innovación". Primero, hay formaciones transparentes que, según Scavnicky, no se emplean en la Península (fregada 'acción de fregar'; pueblada 'acción tumultosa del pueblo'; platada 'lo que cabe en el plato'; orejada 'golpe recibido en la oreja, tirada de oreja'; pechada 'golpe o empujón con el pecho'; negrada 'conjunto, abundancia de negros'; camionada 'capacidad de un camión' ${ }^{32}$. Segundo, los significados tradicionales de

vocablos terminados en -dado y en -tado es algo menor (364 casos de los 2574 , o el $14.2 \%$ ). Para las palabras que terminan en -esa o en -eso (escogidas para establecer una comparación) el porcentaje de $t$ o $d$ delante de la terminación es aún menor, el $10.94 \%$. Pero estos números son engañosos. Son pocas las formaciones en -dada, -tada que se refieran a 'golpes', como saetada 'saetazo', excepto con el morfema -ete, -eta (tijeretada, lancetada); las combinaciones -tazo y -dazo son más numerosas con este significado. De las 404 palabras en -azo, $14(\mathrm{el} 3.5 \%)$ terminan en -dazo y 78 (el 19.3\%) terminan en -tazo; casi la mitad de éstas tienen la forma -etazo (39: uñetazo [pero uñada, uñarada], puñetazo [pero puñada], cucharetazo [cucharada es N6]). Sólo nueve (el 2.2\%) terminan en -zazo, otra combinación desfavorable por la repetición, según Malkiel (p. 201). Existen los sustantivos cabezazo, lanzazo, mazazo y otros, además de las versiones sinónimas en -ada; pero son más frecuentes las palabras en -zada 'golpe', como panzada, hozada, punzada (<punta), pescozada (Diccionario inverso, pp. 54-55).

${ }^{31}$ LEVY, art. cit., p. 418, nota la presencia sistemática de este significado en rumano; véase Georges, Studies, p. 56 y n. 45 sobre -adgo -ado - -ato -aje. En un estudio reciente del uso alfonsí, R. Penny ha indicado que -adgo normalmente se refería a "oficios", faltando el significado fiscal excepto en portadgo. Véase "Derivation of abstracts in Alfonsine Spanish", $R P h, 41$ (1987), p. 8. Sobre la propagación de -aje en general, véase SuzAnNe Fleischman, Cultural and linguistic factors in word formation: An integrated approach to the development of the suffix -age, University of California Press, Berkeley, 1977.

${ }^{32}$ Innovaciones, pp. 26-27, 104. Compárese carrado (normalmente carrada) 'carro lleno', forma citada en Charles E. KanY, Semántica hispanoamericana, trad. L. Escolar Bareño, Aguilar, Madrid, 1962, p. 90. 
- ada se aplican a bases indígenas: comalada 'volumen de granos o cereales que cabe en un comal, el disco bajo y delgado de barro sin vidriar que se usa para cocer las tortillas de maíz, etc.' 33 . El tercer nivel de innovación le da al sufijo - ada significados nuevos: atoleada ( atolada) 'fiesta familiar en que se bebe atol' (< atolear 'convidar para beber atol') $)^{34}$. Se pregunta uno si es semejante un caso como cachupinada 'reunión de gente cursi, banquete'; aunque difiere en su relación con la base, tal vez sea evidencia de la disociación de -ada para indicar 'eventos' en que la base o designa la actividad o nombra a los concurrentes (compárense mascarada 'reunión nocturna de personas enmascaradas' o cabalgata 'reunión de personas que cabalgan juntas'). En otros casos no se trata tanto de innovación como de extensiones paralelas con los datos de los diccionarios consultados en este estudio. Por ejemplo, bejucada 'conjunto de bejucos' no es excepcional por basarse en una raíz que no desigma a animados ${ }^{35}$. El uso peninsular permite el sentido de - $a d a$ 'colectivo absoluto' con plantas u otras entidades que se agrupan, pero limitándose a entidades orgánicas: juncada 'terreno poblado de juncos'; ramada 'conjunto de ramas'; incluso maderada 'conjunto de maderos que se transporta por un río' ‘ ¿Lo mismo podría decirse del ejemplo de Scavnicky, papela$d a$ 'conjunto de paneles'?36. En cambio, alambrada 'red de alambre' es un 'colectivo preparado', un significado mucho más frecuente con los no-animados. Tanıpoco es mnovación total el uso de -ada con matiz 'expansivo/aumentativo', como en correntada o escandalada 'escándalo grande' 37 , que son ejemplos del grupo N2 'intensificador'. El uso de -ada 'confección, colectivo preparado' no se himita a líquidos en el uso normal (cebollada, mantecada), por lo cual cocada 'dulce de coco', aunque sea una formación nueva, es transparente y cabe dentro de las "normas peninsulares"'38. Son excepcionales las formaciones abstraetas, como chulada 'hermosura', pero sí existen ejemplos peninsulares. El uso guatemal-

${ }^{33}$ Scavnicky, Innovaciones, pp. 90-91. Oroz, op. cit., da el ejemplo huinchada $<$ (quichua) huincha, p. 227.

${ }^{34}$ SCAVNICKY, Innovaciones, p. 91.

35 Ibid., p. 92. Otro ejemplo de Scavnicky es estacada (<estaca), que viene del uso peninsular (p. 8).

${ }^{36}$ Ibid., p. 106. Oroz da chorizada 'gran cantidad', p. 227.

${ }^{37}$ SCAVNICKY, Innovaciones, p. 106.

${ }^{38}$ El Diccionario Vox contiene cocada (1) 'dulce de coco' sin mención alguna de regionalismo; pero cocada (2) 'varias preparaciones hechas con coca' se atribuye al Perú (p. 404). 
-ada (V1), por consiguiente, es de tipo distinto del rasgo aspectual que es la base del contraste bailé: bailaba. No obstante, una de las funciones primordiales del sustantivo terminado en - $d o /-d a$ es la de permitir la referencia a una unidad de acción o de masa ('acción y efecto de') o contable. La unidad-masa (para Levy y otros, el "abstracto verbal"), más frecuentemente en - $d a$, se amplía hacia los conceptos concretos de lugar, tiempo e instrumento (entrada). El producto, más frecuentemente en -do, se amplía hacia el objeto pasivo (lavado) y el objeto activo (oido). Compárense sentido 'cosa que percibe' (V5) y sentido 'cosa percibida' (V6). Luego, los empleos denominales de -ada demuestran una expansión en dos direcciones. Primero, de 'unidad de acción' se extiende -ada a 'golpe' y luego a 'acto típico de'42. Segundo, la 'unidad de entidad(es)' se extiende a la relación de colectividad absoluta (yeguada), a la de colectividad confeccionada (limonada) y a la de volumen (cucharada). Más expansiones, como 'golpe dado con' 'golpe dado en' > 'herida o señal residual' > 'dolor de', dan evidencia del dinamismo de estas relaciones y de la vigencia actual de las formaciones descritas, especialmente en el habla popular de América.

El siguiente esquema intenta resumir estas relaciones, sin pretender sugerir la cronología de las expansiones semánticas:

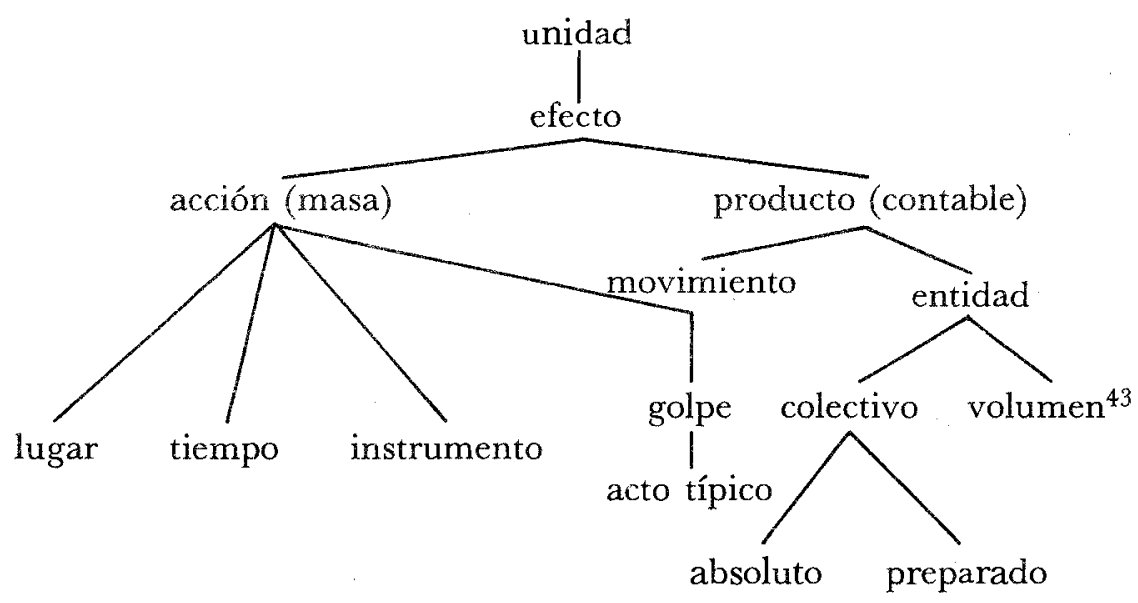

42 Según GEorges, el significado 'acto típico de' era algo raro en el español antiguo y parece ser una extensión del concepto de 'golpe' (Studies, pp. 17, 78).

${ }^{43}$ La noción de 'volumen' representa una especie de colectividad neutra a la distinción absoluto : preparado; la base puede ser el recipiente en el sentido espacial (cucharada) o temporal (otoñada), o puede ser opaca (obrada 'unidad de 
teco de - ado para indicar agente (tamaleada 'mujer que le gusta comer tamales'39) puede ser un caso especial; aunque produce un animado nominalizado, nos interesa por representar una relación oblicua con su base (el caso más parecido es empecinado 'peguero' < pecina < PICINA < PICE 'la pez').

La extensión de -ada no se limita a las regiones americanas. Comparando un diccionario monolingüe de 1913 con uno publicado en 1963, Ralph DeGorog notó que el de 1963 suprimió tomada 'toma', votada 'votación' y levada 'porción de gusanos de seda que se alza y muda de una parte a otra' (aunque Vox todavía da tomada 'conquista por armas de una plaza' y levada, y en el Diccionario de la Real Academia Española de 1984 se encuentran todos estos vocablos). Unas palabras nuevas en -ada 'acto típico de' eran cabronada, domingada (con base no-animada), niñada y portuguesada; en el significado - $a d a$ 'acción de' más infinitivo el diccionario de 1963 incluyó acostada, enviada 'envío' y unos casos más. Es notable también el uso de - $a d a$ en términos técnicos incluidos por primera vez en 1963 (acelerada, cilindrada, embolada). DeGorog concluyó que la expansión de -ada durante esos cincuenta años fue más obvia en el sentido 'acto típico de', mientras que -azo se prefería en el sentido 'golpe' 40 .

Charles Kany observó que el empleo de -ada (V1) con verbos semánticamente débiles (dar, hacer, pegar, echar) forma una perífrasis que permite distinciones aspectuales y numéricas en el tiempo futuro, distinción que enfocan en el pasado los "tiempos" (variantes aspectuales) pretérito e imperfecto ${ }^{41}$. Pero la misma distinción es posible en cualquier tiempo. Di bailadas está en contraste con di una bailada, contraste que no se encuentra en la forma aislada bailé. El rasgo 'contable' aportado por la forma

${ }^{39}$ SCAVNicky, Innovaciones, p. 91.

${ }^{40} \mathrm{R}$. DeGorog, "Trends in Spanish vocabulary", $H, 48$ (1965), p. 647. Según las cifras de DeGorog, la edición del Pequeño Larousse Ilustrado de 1963 añadió veinte ejemplos de palabras en -ada 'acción, golpe', eliminando cuatro. En el significado de 'capacidad, medida' casi no hubo cambio (se eliminaron tres casos y se añadieron cuatro). En un estudio como el de DeGorog (como en el nuestro) las cifras indican solamente unas tendencias generales. La categoría que DeGorog llama 'acción, golpe' requiere más clarificación para que se entienda precisamente en qué función semántica ha tenido lugar cualquier incremento.

${ }^{41}$ Charles E. Kany, Semántica hispanoamericana, p. 87; véase también su American-Spanish syntax, $2^{\text {a }}$ ed., University of Chicago Press, 1951, pp. 15-16. Compárese la expresión dar una vuelta y la alternancia con -azo en fórmulas como echar un vistazo; también, en el inglés informal, take a liking to. 
Pensamos continuar este análisis en el futuro, buscando un refinamiento cuantitativo y una investigación más profunda del residuo. Mientras tanto, esperamos haber identificado importantes funciones de uno de los recursos más productivos y variables de la formación nominal castellana ${ }^{44}$.

BARRY L. Velleman Marquette University

obra(s), labor que en un día hace un hombre cavando la tierra, o una yunta arándola'). En este caso, como en tantos, -ada singulariza, haciendo contables los plurales (una cucharada de pasas), los sustantivos de masa (una cucharada de harina) y los abstractos (dos caidas). 'Volumen', entonces, es una disociación de -ada 'colectivo', combinada felizmente con las nociones de 'singularidad', 'expansión' e 'instrumentalidad', y contrastada con otro producto contable (-ada 'golpe').

$44 \mathrm{El}$ autor quisiera expresarle su gratitud a la señorita Mary MacDermott, Research Assistant en el Departamento de Lenguas Extranjeras de Marquette University, por su ayuda con este proyecto; también a "The Gettel Research Fund" del mismo departamento por su apoyo económico. Una versión preliminar de este estudio se presentó en la Conferencia de Lenguas y Literaturas Románicas de la Universidad de Cincinnati, $\mathrm{OH}$, en mayo de 1985 . 
